\title{
PUEBLOS INDÍGENAS Y CONSOLIDACIÓN DEMOCRÁTICA: DESAFÍOS PARA UN RECONOCIMIENTO CONSTITUCIONAL DE SUS DERECHOS EN CHILE
}

Verónica Figueroa Huencho 


\section{VERÓNICA FIGUEROA HUENCHO}

Doctora en Ciencias de la Gestión por ESADE (España). Realizó sus estudios de postdoctorado en el Centro de Estudios Latinoamericanos de la Universidad de Stanford (EEUU) en el área de políticas públicas indígenas. Profesora Asociada del Instituto de Asuntos Públicos de la Universidad de Chile. Ha sido directora de la Escuela de Gobierno y Gestión Pública de la Universidad de Chile y se ha desempeñado como consultora para el Forum Universal de la Culturas (Barcelona), el Banco Interamericano de Desarrollo y la Organización de Estados Iberoamericanos para la Educación, la Ciencia y la Cultura, entre otros. Sus principales líneas de investigación son las políticas públicas indígenas y la gestión pública intercultural. 


\section{PUEBLOS INDÍGENAS Y CONSOLIDACIÓN DEMOCRÁTICA: DESAFÍOS PARA UN RECONOCIMIENTO CONSTITUCIONAL DE SUS DERECHOS EN CHILE}

\section{INTRODUCCIÓN}

A lo largo de su historia, el Estado chileno ha atravesado diferentes reformas constitucionales que, en mayor o menor medida, han intentado ajustar los mecanismos institucionales y de representación a los desafíos propios de su época. Es así como desde el año 1870, cuando el Congreso Nacional aprobó un conjunto de reformas a la Carta Fundamental que derivaron en cambios a la Constitución de 1833, hasta la discusión que se dio en el año 2005 para generar cambios a la Constitución de 1980, se han evidenciado esfuerzos por introducir en nuestra Carta Magna los requerimientos que exige una democracia en permanente consolidación (Correa, 2015).

En octubre del año 2015, el Gobierno liderado por Michelle Bachelet Jeria (20142018) anunció el inicio de un proceso constituyente orientado a la elaboración de una nueva Constitución Política para Chile. A partir de la discusión y reflexión de la ciudadanía, organizada en "diálogos ciudadanos", se espera contar con insumos para la elaboración de un documento que contenga las "Bases ciudadanas para la Constitución", a partir del cual se pretenden formular los cimientos para un nuevo proyecto constitucional.

Si bien este proceso ha generado grandes expectativas respecto de sus resultados y el alcance de los mismos para toda la ciudadanía, son los pueblos indígenas los que se convierten en un importante actor al encontrar una ventana de oportunidad para instalar en la discusión y en la propia Constitución el reconocimiento de sus derechos como pueblos diferenciados, donde el Estado asuma su carácter plurinacional e intercultural, tal como lo han hecho otros países al considerar la existencia de sus pueblos originarios como un factor sustantivo de apalancamiento de sus cartas fundamentales.

En el caso de Chile, la promesa de este reconocimiento data del año 1989, cuando el entonces candidato presidencial Patricio Aylwin Azócar señalaba en su programa de gobierno el compromiso de adoptar "las medidas destinadas a reconocimiento y preservación por parte del Estado de los pueblos indigenas componentes de la sociedad chilena, valorizando su cultura y su carácter de pueblos integrantes de nuestra nacionalidad. El Estado reconocerá en plenitud sus derechos políticos, sociales, económicos y culturales". Asimismo, se 
asumía como uno de los compromisos firmados en el llamado "Acuerdo de Nueva Imperial" del año 1989, suscrito entre el entonces candidato y los representantes de los pueblos indígenas.

A la fecha, esta promesa aún no se ha cumplido, por lo que el actual proceso constituyente debiera generar los mecanismos para avanzar en esta materia. Más bien, lo que se ha mantenido ha sido el discurso igualitario inmanente al republicanismo que sentó las bases de la construcción del Estado-Nación chileno y que ha servido para justificar la negación de lo indígena al ocultar la situación de desigualdad material en que estos pueblos se han encontrado frente a las "nuevas minorías" que se erigieron como portadoras de esta nueva legitimación del poder, minorías que aún mantienen ese poder (Meza-Lopehandía, 2009).

Tenemos en la actualidad una gran oportunidad de cambiar esto. Sin embargo, como lo demuestran diferentes investigaciones (Figueroa, 2014; 2015), el reconocimiento de derechos hacia los pueblos indígenas desde la Constitución no puede ser entendido como un proceso estandarizado, equiparable al que se ha sumado parte de la sociedad chilena. Más bien, debe dar cabida al reconocimiento de sus diferencias, de su cosmovisión, desde la definición de sus propios mecanismos de discusión hasta la consideración de sus demandas prioritarias producto de reivindicaciones sociales, políticas, económicas y culturales de carácter ancestral que aún no poseen el rango de norma constitucional.

A diferencia de otras reflexiones anteriores, es importante señalar el contexto que genera la ratificación por parte de Chile del Convenio 169 de la OIT ${ }^{1}$ en el año 2008, el que en su artículo $6^{\circ}$ señala que

al aplicar las disposiciones del presente Convenio, los gobiernos deberán: a) consultar a los pueblos interesados, mediante procedimientos apropiados y en particular a través de sus instituciones representativas, cada vez que se prevean medidas legislativas o administrativas susceptibles de afectarles directamente; b) establecer los medios a través de los cuales los pueblos interesados puedan participar libremente, por lo menos en la misma medida que otros sectores de la población, y a todos los niveles en la adopción de decisiones en instituciones electivas y organismos administrativos y de otra índole responsables de políticas y programas que les conciernan; c) establecer los medios para el pleno desarrollo

1. Cabe recordar que el Convenio $\mathrm{N}^{\circ} 169$ ingresó al Congreso en 1991, siendo aprobado con una votación transversal mayoritaria el 11 de abril de 2000 por la Cámara de Diputados. Sin embargo, sería finalmente aprobado por el Senado el 4 de marzo de 2008 por 36 votos a favor y uno en contra, después de 17 años de trámite parlamentario. 
de las instituciones e iniciativas de esos pueblos, y en los casos apropiados proporcionar los recursos necesarios para este fin.

De esta forma, es necesario considerar las opiniones que surgen desde los propios pueblos originarios, donde no resulta suficiente el mero reconocimiento de su preexistencia, sino que es necesario acomodar la institucionalidad del Estado para permitir el legítimo ejercicio de sus derechos colectivos, tal como sucede en el derecho internacional (Meza-Lopehandía, 2010). En ese sentido, la cosmovisión de estos pueblos se convierte en una oportunidad para un adecuado reconocimiento de sus derechos al incorporar miradas, saberes y prácticas hasta ahora no valoradas o invisibilizadas pero que, si fueran reconocidas, permitirían enriquecer los resultados de las decisiones y avanzar hacia la construcción de una verdadera sociedad intercultural, respetuosa de sus pueblos originarios.

En este artículo analizaremos el proceso constituyente que se está llevando a cabo en Chile a partir de los desafíos que supone la consideración de la cosmovisión indígena, en un esfuerzo por incorporar nuevos y mayores elementos a una reflexión de por sí compleja que, sin duda, supera los límites de este proceso, pero que visto en perspectiva de largo plazo podría aportar nuevas miradas al desarrollo de los pueblos indígenas que impacten realmente en la interpretación de los procesos del mundo contemporáneo y las posibilidades de cambio social.

En el siguiente apartado analizaremos los principales sesgos en que han incurrido los procesos de decisión de política pública orientados a los pueblos originarios, junto a los esfuerzos que han realizado diferentes países latinoamericanos por avanzar hacia un mayor reconocimiento de derechos a partir de un breve análisis comparado. A continuación nos pronunciaremos respecto de los principales desafíos que Chile debiera enfrentar en el actual proceso constituyente y el aporte que supone la cosmovisión indígena como un elemento que no puede ser excluido de dicho proceso si se espera avanzar realmente en el reconocimiento de las demandas. Finalmente, se entregará un conjunto de conclusiones orientadas a enriquecer la reflexión colectiva, que permita nutrir de mejor forma el proceso que se está llevando a cabo en nuestro país.

\section{PUEBLOS INDÍGENAS Y ESTADOS: ENFOQUES LIMITADOS PARA UNA REALIDAD COMPLEJA}

Tal como se recoge en diferentes estudios comparados a nivel institucional-nacional, prácticamente la mayoría de los países latinoamericanos ha establecido instituciones públicas destinadas a llevar a cabo políticas sociales referidas tanto a las poblaciones 
como a los pueblos indígenas (Bengoa, 2009). Efectivamente, durante las últimas décadas los pueblos indígenas han adquirido una mayor fuerza y visibilidad producto de una serie de demandas insatisfechas y de reclamaciones que involucran aspectos culturales, territoriales, económicos y/o políticos, entre otros. Esto sugiere no sólo una deficiencia de las políticas públicas, sino que, a lo menos en algunos países de la región, el surgimiento de un nuevo actor social y, en algunos casos, un nuevo actor político que desafía a las formas tradicionales de hacer e implementar la política pública (Bengoa, 2000).

Como señalan Hall y Patrinos (2004:2),

la influencia política de los pueblos indígenas de América Latina, medida según la cantidad de partidos políticos indígenas, representantes electos de origen indígena, disposiciones constitucionales a favor de los pueblos indígenas o políticas de salud y educación, ha crecido durante los últimos 15 años. La democratización, la globalización y las presiones internacionales son razones que pueden explicar este notorio cambio.

Más allá de lo anterior, esta visibilidad no ha derivado en una mejora efectiva de sus condiciones sociales, culturales o políticas, ni ha involucrado una reflexión profunda en torno a las limitantes del liberalismo o del modelo Estado-Nación actual. Más bien, ha sido parte de una retórica que tiende a mantener a los pueblos indígenas en roles secundarios en la toma de decisiones o que viene a reforzar una lógica colonial basada en la negación de la existencia de estos pueblos como verdaderos actores en la toma de decisiones, siendo vistos como culturas que deben ser superadas en pos de avanzar hacia una mayor modernidad (Walsh, 2006).

Por regla general, los pueblos indígenas han estado aislados del proceso de formación estatal y de aquellos que afectan su propio desarrollo, lo que ha significado la pérdida progresiva de tierras, el quiebre de economías comunitarias, la pérdida de derechos y representatividad, y la marginación de procesos políticos, entre otros (Kymlicka, 2003). Por otra parte, se han visto forzados a integrar proyectos políticos que no sólo han negado su carácter de pueblo, sino que también han subvalorado sus capacidades, valores, tradiciones y creencias, siendo construidos a partir de su invisibilización permanente.

El multiculturalismo, como enfoque predominante en las sociedades actuales, no ha considerado en la discusión la posibilidad de cambiar las estructuras y mecanismos en los que se ordenan las sociedades y, por lo tanto, los estados. Los cambios impulsados desde allí han respondido a la perspectiva de aquellos que no quieren perder espacios de poder alcanzados a través de la historia. En ese sentido, 
la decolonialidad intenta refundar las bases del conocimiento y, por tanto, del poder en el que se han llevado adelante los procesos de construcción social.

Diferentes estudios dan cuenta de las limitaciones que el escaso reconocimiento que se ha dado a la cosmovisión de los pueblos indígenas han supuesto a la consolidación de las democracias. Alkire (2005), en un estudio sobre pobreza indígena y políticas públicas, centra su atención en los resultados de las mismas, donde las principales críticas son las siguientes: a) alcance limitado y sesgado de los programas vinculados a las políticas, al no entender adecuadamente la influencia cultural de un pueblo, asumiendo posturas erróneas acerca de determinadas conductas o valores; b) no hay diálogo, sino más bien imposición de valores, intentado deliberadamente cambiar normas culturales o prácticas que se consideran negativas, pero que no son entendidas en contextos culturales diversos; c) existen recursos sin potenciar, especialmente por no tomar en cuenta métodos de trabajo, formas de relación, riqueza cultural, etc., propias de los pueblos indígenas; d) imprevisión de impactos no deseados, pues no han entendido o no han anticipado factores negativos, donde los resultados de las políticas propician, incluso, el empeoramiento de las circunstancias que se esperaban resolver.

Hall y Patrinos (2004) señalan en el informe del Banco Mundial sobre indígenas y pobreza en América Latina ${ }^{2}$ que

no existe duda en que los pueblos indígenas se relacionan con bajo nivel de educación, condiciones deficientes en términos de nutrición y salud, desempleo y discriminación, entre otros, los que se analizan generalmente como elementos constitutivos de la "pobreza". Sin embargo, los pueblos indígenas también se consideran a sí mismos ricos en materia de tradiciones culturales y espirituales, a las que la sociedad en general suele asignar mucho menos valor y que no se prestan para mediciones cuantitativas, por lo que no son incluidos en la formulación de políticas públicas.

Una reciente investigación del Banco Mundial (2014) indica que las políticas públicas indígenas requieren ser repensadas en todas sus etapas, especialmente en la formulación, implementación y evaluación. Las deficiencias de las políticas se expresan en que, actualmente, los indígenas representan alrededor del $14 \%$ de los pobres (que viven con menos de cuatro dólares al día) y $17 \%$ de todos los latinoamericanos que viven con menos de 2,50 dólares al día, pese a que representan el $7 \%$ de la población. Agregan que la expansión cuantitativa de una serie de servicios

2. Pueblos indígenas, pobreza y desarrollo en América Latina: 1994-2004. 
públicos para incluir a los hogares indígenas no siempre ha ido acompañada de un cambio cualitativo que realmente ayude a los pueblos indígenas a decidir su propio rumbo de desarrollo y a vencer la exclusión que siguen padeciendo. A pesar de las extensas leyes y reglamentos destinados a proteger las lenguas y culturas originarias, así como el reconocimiento generalizado de la importancia de incluir estrategias de educación intercultural bilingüe en el sistema escolar, en la actualidad la participación escolar entre indígenas está fuertemente asociada a la pérdida de sus lenguas (Banco Mundial, 2014).

Lo anterior ha influido de manera importante en la visión con la que se han llevado adelante las iniciativas de desarrollo en América Latina respecto de los pueblos indígenas, donde la modernidad ha recalcado la linealidad en la búsqueda de un mejor estado de vida para las poblaciones. Es así como el propio término desarrollo está a menudo cargado de connotaciones que lo relacionan con la idea moderna de "progreso", la que ha sido ampliamente criticada por diversos pensadores contemporáneos que ven en este concepto el origen de muchos de los males que sufre gran parte de la humanidad (Martínez Navarro, 2000).

Por lo tanto, la evidencia muestra que ha existido una visión sesgada de los problemas que afectan a los pueblos indígenas, aportando soluciones que se definen, construyen e implementan desde la mirada occidental y que tienen como resultado el surgimiento de nuevas reivindicaciones. La desconexión entre la formulación de la política pública y su consecuente implementación parece constituir un factor relevante a la hora de evaluar el impacto (positivo o negativo) que una política tendrá para los pueblos indígenas.

Sin embargo, más allá de estas limitaciones, la emergencia de movimientos indígenas en Latinoamérica en los años '90 posicionó en la agenda política de diferentes países la necesidad de generar cambios estructurales, viendo en la conquista de niveles altos de autogobierno la posibilidad de ejercitar sus derechos a la autodeterminación política, económica y cultural. Es así como estos movimientos lograron resituar la cuestión étnica de una manera novedosa, obligando a los estados a incluir la dimensión étnica en sus debates, lo que se demuestra en diferentes cuerpos legales y de manera fundamental en sus constituciones.

\subsection{PUEBLOS INDÍGENAS Y RECONOCIMIENTO DE DERECHOS EN LATINOAMÉRICA:ANÁLISIS COMPARADO ANIVELCONSTITUCIONAL}

Durante el último tiempo han sido varios los gobiernos latinoamericanos que han debido enfrentar, de una u otra manera, las consecuencias de políticas definidas sin los pueblos indígenas, reemergiendo demandas en muchos casos de carácter 
ancestral, aun cuando no formaban parte de una agenda política o ideológica oficial, e impulsando la revisión de conceptos como Estado-Nación o la propia democracia (Kelly, 2002). En ese sentido, los cambios que se han promovido han sido principalmente de carácter legal, al reconocer en las constituciones políticas a los pueblos indígenas o al ratificar instrumentos normativos internacionales que propicien una mayor participación de estos pueblos en los procesos de decisión.

Una breve revisión de algunas reformas constitucionales recientes ha enfatizado la noción de que la unidad no implica homogeneización de las diferencias culturales, como algunas constituciones lo habían entendido en décadas anteriores. En consecuencia, han comenzado a definir a sus estados como multiétnicos y multiculturales, estableciendo la promoción de la diversidad como un principio constitutivo de sus cartas magnas (Uprimny, 2011).

De acuerdo con algunos autores, los alcances del reconocimiento constitucional de los pueblos indígenas han sido variados (Henríquez, 2005), desde aquellos que han ido desde el mínimo e imprescindible reconocimiento de la multiculturalidad del Estado hasta el derecho de los indígenas a la educación bilingüe. Por otra parte, algunas constituciones han reconocido a los pueblos indígenas como pueblos originarios y preexistentes; y la propiedad de sus tierras, como recurso material, cultural y soporte político de la existencia de aquéllos.

También han considerado derechos a la identidad y cultura propia, el derecho a conservarla, desarrollarla y transmitirla; a la autodeterminación o autogobierno según sus usos y costumbres; a la administración privilegiada sobre los recursos naturales existentes en sus territorios; a la religión ancestral como factor de identificación étnico-cultural; a tener formas propias de organización social; a la participación en la política local y nacional mediante la elección de sus propios representantes; a ser consultados cada vez que se promuevan medidas legislativas y administrativas susceptibles de afectarlos; y a adaptar la justicia a los sistemas indígenas utilizando sus usos y costumbres, entre otros derechos (Henríquez, 2005: pp:4).

De acuerdo con Nash y Núñez (2015), es posible establecer una comparación entre diferentes constituciones latinoamericanas a partir de diferentes variables como los alcances del reconocimiento, conceptos y principios, así como de los derechos reconocidos en esas constituciones, como participación política, derecho consuetudinario indígena, propiedad indígena y recursos naturales, entre otros. Sin el ánimo de hacer una comparación exhaustiva, de los casos revisados por estos autores es posible extraer algunos elementos interesantes de análisis para el caso chileno: 
Tabla 1: Comparación sobre "Alcances del reconocimiento a los pueblos indígenas"

\begin{tabular}{|c|c|c|c|}
\hline & $\begin{array}{l}\text { Conceptos } \\
\text { relevantes }\end{array}$ & Autodeterminación & Principios \\
\hline Bolivia & $\begin{array}{l}\text { Existencia } \\
\text { de pueblos } \\
\text { indígenas }\end{array}$ & $\begin{array}{l}\text { Art. 2: "Dada la existencia } \\
\text { precolonial de las naciones y } \\
\text { pueblos indígenas originarios [...] } \\
\text { se garantiza su libre determinación } \\
\text { en el marco de la unidad del Estado, } \\
\text { que consiste en su derecho a la } \\
\text { autonomía, al autogobierno, a su } \\
\text { cultura, al reconocimiento de sus } \\
\text { instituciones y a la consolidación de } \\
\text { sus entidades territoriales [...]" }\end{array}$ & $\begin{array}{l}\text { Art. 1: "Estado Unitario social } \\
\text { de derecho, plurinacional, } \\
\text { comunitario, }[\ldots] \text { intercultural, } \\
\text { descentralizado y con } \\
\text { autonomías. Bolivia se funda } \\
\text { en la pluralidad y el pluralismo } \\
\text { político, económico, jurídico, } \\
\text { cultural y lingüístico del } \\
\text { proceso integrador del país" }\end{array}$ \\
\hline Colombia & $\begin{array}{l}\text { Existencia } \\
\text { de pueblos } \\
\text { indígenas }\end{array}$ & $\begin{array}{l}\text { Art. 287: "Las entidades territoriales } \\
\text { (dentro de las cuales se encuentran } \\
\text { los territorios indígenas) gozan de } \\
\text { autonomía para la gestión de sus } \\
\text { intereses, dentro de los límites de la } \\
\text { Constitución y la Ley" }\end{array}$ & $\begin{array}{l}\text { Art. 7: "Reconoce y protege la } \\
\text { diversidad ética y cultural de la } \\
\text { nación colombiana" }\end{array}$ \\
\hline Venezuela & $\begin{array}{l}\text { Existencia } \\
\text { de pueblos } \\
\text { indígenas }\end{array}$ & $\begin{array}{l}\text { Art. 119: "El Estado reconocerá } \\
\text { la existencia de los pueblos } \\
\text { y comunidades indígenas, su } \\
\text { organización social, política } \\
\text { y económica, sus culturas y } \\
\text { costumbres, idiomas, religiones, } \\
\text { así como su hábitat y derechos } \\
\text { originarios sobre las tierras que } \\
\text { ancestral y tradicionalmente ocupan" }\end{array}$ & $\begin{array}{l}\text { Art. 100: "Reconoce y respeta } \\
\text { la interculturalidad bajo el } \\
\text { principio de igualdad de las } \\
\text { culturas" }\end{array}$ \\
\hline Ecuador & $\begin{array}{l}\text { Existencia } \\
\text { de pueblos } \\
\text { indígenas }\end{array}$ & $\begin{array}{l}\text { Art. 60: "Los pueblos ancestrales, } \\
\text { indígenas, afroecuatorianos y } \\
\text { montubios podrán constituir } \\
\text { circunscripciones territoriales para } \\
\text { la preservación de su cultura }[. . .] \text { Se } \\
\text { reconoce a las comunas que tienen } \\
\text { propiedad colectiva de la tierra, } \\
\text { como una forma de organización } \\
\text { ancestral" }\end{array}$ & $\begin{array}{l}\text { Art. 1: "Es un Estado } \\
\text { constitucional de derechos y } \\
\text { justicia, social, democrático, } \\
\text { soberano, independiente, } \\
\text { unitario, intercultural, } \\
\text { plurinacional y laico" }\end{array}$ \\
\hline
\end{tabular}




\begin{tabular}{|l|l|l|l}
\hline \multicolumn{1}{|l|}{$\begin{array}{l}\text { Conceptos } \\
\text { relevantes }\end{array}$} & Autodeterminación & Principios \\
\hline Perú & $\begin{array}{ll}\text { Existencia de } \\
\text { comunidades } \\
\text { nativas }\end{array}$ & $\begin{array}{l}\text { Art. 88: "Las comunidades } \\
\text { campesinas y las nativas son } \\
\text { autónomas en su organización, en el } \\
\text { trabajo comunal y en el uso y la libre } \\
\text { disposición de sus tierras, así como } \\
\text { en lo económico y administrativo, } \\
\text { dentro del marco que la ley } \\
\text { establece" }\end{array}$ & $\begin{array}{l}\text { Art. 2: "Reconoce a las } \\
\text { personas su derecho a la } \\
\text { identidad étnica y cultural } \\
\text { pluralidad étnica y cultural de } \\
\text { la nación" }\end{array}$ \\
\hline
\end{tabular}

Fuente: Elaboración propia en base a Nash y Núñez (2015)

La tabla precedente permite evidenciar que, en los últimos años, tanto los cambios en el marco internacional como la consolidación de las democracias en varios países latinoamericanos han ido reconfigurando de alguna manera el rol de los pueblos indígenas, quienes han comenzado a abrir espacios para la generación de movimientos que reclaman, entre otros aspectos, el reconocimiento de derechos políticos, sociales y culturales junto con la defensa y recuperación de sus territorios ancestrales (Bengoa, 2000). Este nuevo escenario es relevante para el conjunto de las sociedades latinoamericanas y para el futuro de la democracia, pues plantea el desafío de repensar la comunidad política, los mecanismos de inclusión ciudadana, los modelos de sociedad preponderantes y los modelos de formulación e implementación de políticas públicas que se han definido para los pueblos indígenas.

Entre los elementos más relevantes de la discusión, tal como se menciona en la tabla, se encuentra el concepto de "pueblo". En ese sentido, el Convenio $\mathrm{N}^{\circ}$ 169 de la OIT señala en su artículo $1^{\circ}$ a) que este convenio se aplica a "los pueblos tribales en países independientes, cuyas condiciones sociales, culturales y económicas les distingan de otros sectores de la colectividad nacional, y que estén regidos total o parcialmente por sus propias costumbres o tradiciones o por una legislación especial". Otro instrumento relevante en la definición de pueblos es la Declaración de Derechos de Pueblos Indígenas de la Asamblea General de Naciones Unidas, que en su artículo $1^{\circ}$ señala que "los indígenas tienen derecho, como pueblos o como personas, al disfrute pleno de todos los derechos humanos.

En el caso de Chile, el propio Tribunal Constitucional se ha referido al concepto de pueblo, donde indica que éste deber ser entendido como

un conjunto de personas o grupos de personas de un país que poseen en común características culturales propias, que no se encuentran dotadas de potestades públicas y que tienen y tendrán derecho a participar y a ser consultadas, en 
materias que les conciernan, con estricta sujeción a la Ley Suprema del respectivo Estado de cuya población forman parte ${ }^{3}$.

Por lo tanto, no puede existir un real proceso de discusión constituyente si no se incluye en la agenda de discusión este concepto, el reconocimiento del carácter de pueblos de los diferentes grupos indígenas que habitan el territorio, y que supone la adquisición de derechos específicos en cuanto esa condición.

Como señala Meza-Lopehandía (2010), la actual Constitución chilena dificulta el ejercicio de una verdadera democracia, especialmente el cumplimiento de los derechos de los pueblos indígenas. En Chile sólo se reconoce la existencia de una nación, pero es necesario considerar en ella la existencia de diferentes pueblos, cuestión que se ve compleja, ya que nuestra Carta Magna reconoce un solo pueblo que ejercita la soberanía, excluyendo a los pueblos indígenas del cuerpo político.

Otro concepto relevante es el de autodeterminación. En ese sentido, supone el reconocimiento de derechos colectivos, tal como se expresa en el Pacto Internacional de Derechos Económicos, Sociales y Culturales, y el Pacto Internacional de Derechos Civiles y Políticos, donde se señala que "Todos los pueblos tienen el derecho a la libre determinación; en virtud de este derecho, determinan libremente su condición política y persiguen libremente su desarrollo económico, social y cultural". Por su parte, la Declaración de Derechos de los Pueblos Indígenas señala en su artículo $3^{\circ}$ que "los pueblos tienen derecho a la libre determinación y en virtud de ese derecho determinan libremente su condición politica y persiguen libremente su desarrollo económico, social y cultural'.

Este ha sido uno de los puntos más complejos del reconocimiento de derechos de los pueblos indígenas, y Chile no es la excepción. Durante la discusión de la ley $\mathrm{N}^{\mathrm{o}} 19.253$ éste fue uno de los principales escollos para darles el reconocimiento de pueblos, pues se entendía que dicho reconocimiento podía derivar en demandas de autonomía que "pondrían en peligro la unidad del Estado chileno y, con ello, el germen de su desintegración" (Figueroa, 2014). Sin embargo, es necesario incluir en la discusión este punto, que ha sido núcleo de demandas desde diferentes sectores del movimiento indígena.

Finalmente, el reconocimiento de la diversidad cultural del Estado en términos de reconocerse como plurinacional e intercultural resulta igualmente significativo, en el entendido que esto tiene incidencia en las políticas públicas, leyes, normas y características del entramado institucional que permitirá concretar las aspiraciones

3. Requerimiento respecto del Convenio $\mathrm{N}^{\circ} 169$, Rol $\mathrm{N}^{\circ}$ 309-2000, 4 de agosto de 2000, Considerando $44^{\circ}$. 
constitucionales para los pueblos indígenas. Como señala la Unesco, la diversidad cultural supone la

multiplicidad de medios por los que se expresan las culturas de los grupos sociales y sociedades. De las diversas formas revestidas por la cultura a lo largo del tiempo y del espacio emanan la originalidad y la multiplicidad de las identidades y expresiones culturales de los pueblos y sociedades que forman la humanidad.

Un adecuado reconocimiento de derechos en esa materia impedirá el surgimiento de lo que Charles Hale (2006) denomina "multiculturalismo neoliberal". En estos modelos son aquellos actores que siempre han detentado el poder quienes no están dispuestos a propiciar cambios reales en las estructuras, entregando mínimos espacios para el acomodo cultural y limitando iniciativas que provengan de los propios pueblos indígenas. De esa forma, aspiraciones legítimas por transformar la distribución social de los recursos o por promover el surgimiento de nuevos y/o mayores acuerdos políticos para sustentar dichas transformaciones se ven intencionalmente restringidas.

Siguiendo con los aportes de Nash y Núñez (2015), podemos establecer una comparación entre las principales constituciones en torno a los derechos que allí se consagran, entre los que podemos destacar los siguientes: 
Tabla 2: Comparación sobre "Derechos de los pueblos indígenas"

\begin{tabular}{|c|c|c|c|}
\hline & Participación política & $\begin{array}{l}\text { Derecho } \\
\text { consuetudinario }\end{array}$ & Propiedad indígena \\
\hline Bolivia & $\begin{array}{l}\text { Art. 11: "Por medio de } \\
\text { la elección, designación } \\
\text { o nominación } \\
\text { de autoridades y } \\
\text { representantes por } \\
\text { normas y procedimientos } \\
\text { propios de las naciones } \\
\text { y pueblos indígenas } \\
\text { originario campesinos } \\
{[\ldots]}\end{array}$ & $\begin{array}{l}\text { Art. 30: "Derecho a } \\
\text { gozar del ejercicio de } \\
\text { sus sistemas políticos, } \\
\text { jurídicos y económicos } \\
\text { de acuerdo a su } \\
\text { cosmovisión" } \\
\text { Art. 190: "La jurisdicción } \\
\text { indígena originaria } \\
\text { campesina respeta el } \\
\text { derecho a la vida, el } \\
\text { derecho a la defensa } \\
\text { y demás derechos y } \\
\text { garantías establecidos en } \\
\text { la presente Constitución" }\end{array}$ & $\begin{array}{l}\text { Art. 394: "El Estado } \\
\text { reconoce, protege y garantiza } \\
\text { la propiedad comunitaria o } \\
\text { colectiva, que comprende el } \\
\text { territorio indígena originario } \\
\text { campesino, las comunidades } \\
\text { interculturales originarias } \\
\text { y de las comunidades } \\
\text { campesinas. La propiedad } \\
\text { colectiva se declara } \\
\text { indivisible, imprescriptible, } \\
\text { inembargable, inalienable e } \\
\text { irreversible y no está sujeta } \\
\text { al pago de impuestos a } \\
\text { la propiedad agraria. Las } \\
\text { comunidades podrán ser } \\
\text { tituladas reconociendo } \\
\text { la complementariedad } \\
\text { entre derechos colectivos } \\
\text { e individuales respetando } \\
\text { la unidad territorial con } \\
\text { identidad" }\end{array}$ \\
\hline Colombia & $\begin{array}{l}\text { Art. 171: "El Senado } \\
\text { de la República estará } \\
\text { integrado por cien } \\
\text { miembros elegidos } \\
\text { en circunscripción } \\
\text { nacional. Habrá un } \\
\text { número adicional de dos } \\
\text { senadores elegidos en } \\
\text { circunscripción nacional } \\
\text { especial por comunidades } \\
\text { indígenas" }\end{array}$ & $\begin{array}{l}\text { Art. 246: "Las } \\
\text { autoridades de los } \\
\text { pueblos indígenas } \\
\text { podrán ejercer funciones } \\
\text { jurisdiccionales dentro } \\
\text { de su ámbito territorial, } \\
\text { de conformidad con } \\
\text { sus propias normas y } \\
\text { procedimientos, siempre } \\
\text { que no sean contrarios } \\
\text { a la Constitución y leyes } \\
\text { de la República. La ley } \\
\text { establecerá las formas } \\
\text { de coordinación de esta } \\
\text { jurisdicción especial } \\
\text { con el sistema judicial } \\
\text { nacional" }\end{array}$ & $\begin{array}{l}\text { Art. 330: "De conformidad } \\
\text { con la Constitución y las leyes, } \\
\text { los territorios indígenas estarán } \\
\text { gobernados por consejos } \\
\text { conformados y reglamentados } \\
\text { según los usos y costumbres de } \\
\text { sus comunidades y ejercerán } \\
\text { las siguientes funciones [...]" }\end{array}$ \\
\hline
\end{tabular}




\begin{tabular}{|c|c|c|c|}
\hline & Participación política & $\begin{array}{l}\text { Derecho } \\
\text { consuetudinario }\end{array}$ & Propiedad indígena \\
\hline Venezuela & $\begin{array}{l}\text { Art. 125: "Los pueblos } \\
\text { indígenas tienen derecho } \\
\text { a la participación política. } \\
\text { El Estado garantizará } \\
\text { la representación } \\
\text { indígena en la Asamblea } \\
\text { Nacional y en los } \\
\text { cuerpos deliberantes de } \\
\text { las entidades federales } \\
\text { y locales con población } \\
\text { indígena, conforme a la } \\
\text { ley" }\end{array}$ & $\begin{array}{l}\text { Art. 119: "Pueden } \\
\text { ejercer funciones } \\
\text { jurisdiccionales dentro } \\
\text { de ámbito territorial } \\
\text { de conformidad con el } \\
\text { derecho consuetudinario, } \\
\text { siempre que no violen los } \\
\text { derechos fundamentales } \\
\text { de la persona }[. . .] "\end{array}$ & $\begin{array}{l}\text { Art. 119: "Corresponderá } \\
\text { al Ejecutivo Nacional, } \\
\text { con la participación de los } \\
\text { pueblos indígenas, demarcar } \\
\text { y garantizar el derecho a } \\
\text { la propiedad colectiva de } \\
\text { sus tierras, las cuales serán } \\
\text { inalienables, imprescriptibles, } \\
\text { inembargables e intransferibles } \\
\text { de acuerdo con lo establecido } \\
\text { en esta Constitución y en la } \\
\text { ley" }\end{array}$ \\
\hline Ecuador & $\begin{array}{l}\text { Art. 57: "Participar } \\
\text { mediante sus } \\
\text { representantes en los } \\
\text { organismos oficiales } \\
\text { que determine la ley } \\
\text { en la definición de } \\
\text { políticas públicas que les } \\
\text { conciernan, así como en } \\
\text { el diseño y decisión de sus } \\
\text { prioridades en los planes y } \\
\text { proyectos del Estado" }\end{array}$ & $\begin{array}{l}\text { Art. } 57, N^{\circ} 10 \text { : "Crear, } \\
\text { desarrollar, aplicar y } \\
\text { practicar su derecho } \\
\text { propio o consuetudinario, } \\
\text { que no podrá vulnerar } \\
\text { derechos constitucionales, } \\
\text { en particular de las } \\
\text { mujeres, niñas, niños y } \\
\text { adolescentes" }\end{array}$ & $\begin{array}{l}\text { Art. 57: "Participar en el uso, } \\
\text { usufructo, administración y } \\
\text { conservación de los recursos } \\
\text { naturales renovables que se } \\
\text { hallen en sus tierras" }\end{array}$ \\
\hline Perú & $\begin{array}{l}\text { Art. 191: "La ley establece } \\
\text { porcentajes mínimos } \\
\text { para hacer accesible } \\
\text { la representación de } \\
\text { género, comunidades } \\
\text { campesinas y nativas y } \\
\text { pueblos originarios en los } \\
\text { consejos regionales. Igual } \\
\text { tratamiento se aplica a los } \\
\text { consejos municipales" }\end{array}$ & $\begin{array}{l}\text { Art. 149: "Las } \\
\text { autoridades de } \\
\text { las Comunidades } \\
\text { Campesinas y } \\
\text { Nativas, con el } \\
\text { apoyo de las Rondas } \\
\text { Campesinas, pueden } \\
\text { ejercer las funciones } \\
\text { jurisdiccionales dentro } \\
\text { de su ámbito territorial } \\
\text { de conformidad con el } \\
\text { derecho consuetudinario, } \\
\text { siempre que no violen los } \\
\text { derechos fundamentales } \\
\text { de la persona. La ley } \\
\text { establece las formas de } \\
\text { coordinación de dicha } \\
\text { jurisdicción especial con } \\
\text { los Juzgados de Paz y con } \\
\text { las demás instancias del } \\
\text { Poder Judicial" }\end{array}$ & $\begin{array}{l}\text { Art. 88: "Las Comunidades } \\
\text { Campesinas y las Nativas } \\
\text { tienen existencia legal y son } \\
\text { personas jurídicas" }\end{array}$ \\
\hline
\end{tabular}

Fuente: Elaboración propia en base a Nash y Núñez (2015) 
Entre los principales elementos que nos muestra la tabla precedente se encuentra el de participación política, que va unido de manera importante al concepto de autodeterminación en el sentido de permitir la generación de espacios específicos que aseguren que sean los pueblos indígenas quienes tomen sus propias decisiones y puedan actuar de manera libre e informada respecto de todos aquellos factores que afectan su propio desarrollo. Como se señaló en el apartado anterior, gran parte de los errores en los que han incurrido las políticas públicas dirigidas a los pueblos indígenas es que no han sido formuladas respetando su cosmovisión, siendo ellos actores marginales del proceso.

Asimismo, el derecho consuetudinario supone incorporar a la discusión el concepto de territorio en torno al ejercicio efectivo de derechos y a la autodeterminación, así como el de propiedad indígena. En ese contexto la posición más extendida ha sido la que entiende que el ejercicio de la autodeterminación territorial no supone la creación de un Estado dentro de un Estado o que se separa de éste, sino de un ámbito territorial en que los pueblos indígenas pueden dirigir por sí mismos su vida interna, a través de instituciones y costumbres propias (MezaLopehandía, 2010).

En ese contexto, el artículo $26^{\circ}$ de la Declaración de las Naciones Unidas sobre los Derechos de los Pueblos Indígenas señala que

Los pueblos indígenas tienen derecho a las tierras, territorios y recursos que tradicionalmente han poseído, ocupado, adquirido [...] los pueblos indígenas tienen derecho a poseer, desarrollar y controlar las tierras, territorios y recursos que poseen en razón de la propiedad tradicional u ocupación o utilización [...] los Estados asegurarán el reconocimiento y protección jurídica de estas tierras, territorios y recursos. Dicho reconocimiento respetará debidamente las costumbres, tradiciones y los sistemas de tenencia de tierras de los pueblos indígenas.

Por su parte, el artículo $14^{\circ}$ del Convenio 169 de la OIT señala que

Deberá reconocerse a los pueblos interesados el derecho de propiedad y de posesión sobre las tierras que tradicionalmente ocupan. Además, en los casos apropiados, deberán tomarse medidas para salvaguardar el derecho de los pueblos interesados a utilizar tierras que no estén exclusivamente ocupadas por ellos, pero a las que hayan tenido tradicionalmente acceso para sus actividades tradicionales y de subsistencia" y que "los gobiernos deberán tomar las medidas que sean necesarias para determinar las tierras que los pueblos interesados 
ocupan tradicionalmente y garantizar la protección efectiva de sus derechos de propiedad y posesión.

Como se evidencia en diferentes estudios, la mayoría de los proyectos de reforma constitucional que se han propuesto en los últimos años han optado por utilizar el concepto de "tierras indígenas", dejando a un lado la incorporación de la noción de territorio indigena. Sin embargo, la diferencia entre ambos conceptos es sustantiva desde el punto de vista del ejercicio de los derechos de los pueblos indígenas. En el caso de Chile, esta discusión no ha sido adecuadamente considerada. Como se describe en algunas investigaciones, el reconocimiento del territorio no fue considerado en la ley $\mathrm{N}^{\circ} 19.253$, donde la solución se acotaba a la propiedad individual del terreno y a la regularización de su tenencia por parte de las comunidades. Es así como se habla de "tierras indígenas", cuya propiedad tendrá como titulares a las personas naturales indígenas o a la comunidad indígena definida por la propia ley.

Junto con ello, se reconoce el rol del Estado de "proteger las tierras indígenas, velando por su adecuada explotación, por su equilibrio ecológico y propendiendo a su ampliación". Con ello se da inicio a uno de los puntos en conflicto que permanecerá hasta los gobiernos actuales y que ha formado parte de las demandas permanentes de los pueblos indígenas: la restitución del territorio ancestral como sustento del desarrollo de los pueblos indígenas (Figueroa, 2014).

Efectivamente, para subsanar aspectos vinculados al territorio, la ley habla del reconocimiento de "áreas de desarrollo indígena", donde corresponderá al ministerio de Planificación y Cooperación ${ }^{4}$ (a propuesta de la Corporación) establecer áreas de desarrollo indígena que serán "espacios territoriales en que los organismos de la administración del Estado focalizarán su acción en beneficio del desarrollo armónico de los indígenas y sus comunidades", con lo cual el concepto de comunidad no se ve reflejado, rompiendo así un elemento fundamental de la cultura y existencia indígena. Para algunos sectores del Ejecutivo, el elemento cultural ya estaba implícito en la "prohibición de vender tierras a no indígenas", elemento más que suficiente para respetar su cosmovisión (Entrevista a ex asesor, 2012, en Figueroa 2014). Posiciones como éstas aún existen en la clase política chilena.

El breve análisis comparado que se ha presentado permite evidenciar que si bien existen avances en las constituciones que han derivado en adecuaciones en otras materias formales de política pública indígena y de las instituciones que, de una u otra manera, definen, promueven y/o articulan las decisiones que se dirigen a estos pueblos (Fondo Indígena, 2007), aún queda mucho camino por recorrer,

4. Actual ministerio de Desarrollo Social 
especialmente para dar cabida a las particularidades de los pueblos indígenas en términos de su cosmovisión.

Las tablas precedentes recogen algunas de las principales dimensiones que deben ser consideradas al momento de discutir respecto del reconocimiento constitucional de los pueblos indígenas, para no caer en visiones sesgadas que sólo reconozcan aquellas miradas de las sociedades dominantes, las que, en muchos casos, no están dispuestas a abrir espacios en la toma de decisiones, especialmente aquellas de carácter político. En ese contexto, el paradigma multicultural que ha servido de parámetro para la toma de decisiones en torno a las políticas públicas indígenas en la mayoría de los Estados-Nación (como es el caso de Chile ${ }^{5}$ ha comenzado a demostrar su debilidad al privilegiar modelos de sociedad que no pretenden cambios de fondo, sino que se sustentan en un liberalismo que, en pos del respeto a las diferencias, continúa acrecentando las brechas entre quienes tienen el poder efectivo de decidir qué espacios de acción se permitirán, qué valores se priorizarán o qué culturas se considerarán, frente a aquellas que, aun cuando han habitado históricamente un territorio, no cuentan con el poder político que les permita conducir sus propios destinos o, al menos, incidir en sus contenidos y alcances (Álvarez, 2010).

En ese sentido, la lógica ha sido que las sociedades dominantes son las que definen los parámetros, contenidos y alcances respecto de los que se debe discutir y de lo que, finalmente, formará parte de la decisión política. Por lo tanto, no basta con evidenciar o cuantificar la cantidad de organismos existentes o las políticas sectoriales y generales que se desarrollan en torno a ellos, o los programas específicos implementados, si realmente éstos no representan las demandas y aspiraciones de los pueblos indígenas, con la complejidad que ello supone.

Las reivindicaciones de los pueblos indígenas en la actualidad abogan más bien por una reconstrucción de América Latina que ponga en cuestionamiento los ideales de nación y de Estado en los que se han basado las propuestas desde la propia colonización, concebidas desde una mirada occidental que constituye sólo una cara de la moneda. El multiculturalismo ha demostrado sus limitaciones y se requiere una apertura hacia nuevas propuestas, nuevos modelos que realmente promuevan el empoderamiento de los pueblos indígenas como una deuda histórica que requiere ser saldada.

5. Incluso cuando no se ha adoptado el modelo de forma explícita, el análisis de diferentes instrumentos y documentos da cuenta de que se trata de un modelo limitado de multiculturalismo (Figueroa, 2014). 


\section{2 ¿NUEVAS OPORTUNIDADES PARA CHILE? LOS DESAFÍOS DEL PROCESO CONSTITUYENTE A LA LUZ DE LA EXPERIENCIA LATINOAMERICANA}

El análisis comparado permite extraer importantes aprendizajes para el caso de Chile en el sentido de explicitar los elementos básicos que deben ser sujetos de discusión en una reforma constitucional que realmente considere la cosmovisión, demandas y necesidades de los pueblos indígenas. En el caso de Chile, si bien se ha avanzado en términos de gobernabilidad y de desarrollo humano que han redundado en mejoras a las condiciones de vida de las personas, la democracia (como régimen político) es un ideal que inspira el perfeccionamiento institucional constante y que, por esa razón, ha ido encontrado limitaciones que impiden avanzar en su perfeccionamiento y en su capacidad para promover una igualdad efectiva (PNUD, 2015).

Desde los '80, los pueblos indígenas han buscado relevar espacios de acción y participación construidos desde su propia cosmovisión, pero que se vieron obstaculizados por sistemas institucionales diseñados para canalizar y representar intereses muchas veces contradictorios con aquellos esperados por estos pueblos. La representación a través de partidos políticos, la defensa de una visión occidental de desarrollo y la gobernabilidad basada en la negociación con grupos de interés diversos, se vieron enfrentados a los intereses de los pueblos indígenas, marcados por la defensa del territorio, la cultura como punto de apalancamiento para su desarrollo y la búsqueda de sistemas de participación y representación pertinentes, entre otros.

Es así como la vuelta a la democracia, en el año 1990, ha marcado gran parte de la agenda política en torno a los pueblos indígenas de los últimos tiempos, cuando es posible evidenciar las principales dificultades de éstos por asumir un rol protagónico como actores políticos de su propio destino. Los cambios producidos en el entorno, la apertura de canales de participación y comunicación hacia los niveles políticos, junto con la dinámica producida por la entrada de nuevos actores al proceso de decisión política, parecían dar inicio a nuevos enfoques en torno a las políticas públicas indígenas.

En ese contexto, el nuevo escenario democrático generó expectativas para estos pueblos en términos de resolver demandas insatisfechas y encontrar espacios donde su propia cosmovisión fuera considerada un factor en la toma de decisiones. Sin embargo, las diferencias en torno a la definición del problema y las consecuentes alternativas y estrategias de acción se convertirían en elementos que luego incidieron en los pobres resultados que ha tenido la política indígena en Chile, donde no se 
han cuestionado las prácticas, relaciones o sentidos que constituyen el poder para este caso (Quijano, 2000).

Aún más, si bien han pasado más de 20 años del retorno a la democracia, la sociedad chilena aún les desconoce el carácter de "pueblos indígenas", refiriéndose en la ley respectiva ( $\mathrm{N}^{\circ} 19.253$ del año 1994) a la existencia de "etnias". Sin embargo, dado el posicionamiento que asumimos en este artículo, se hablará de pueblos indígenas para dar cuenta de un concepto más amplio, a través del que se reconoce en ellos la existencia de un territorio habitado históricamente; la existencia de una cosmovisión propia, con cultura y lengua diferenciadas; la existencia de instituciones sociales, políticas, económicas y culturales que aún persisten; la conciencia de pueblo extendida y defendida en sus demandas ancestrales; y el sentido compartido por preservar estos elementos (Figueroa, 2007).

Recientes investigaciones han mostrado que, para el caso chileno, las decisiones políticas para los pueblos indígenas se han construido desde una sola visión, la "occidental" o de la sociedad dominante, invisibilizando saberes ancestrales, instituciones y autoridades tradicionales, entre otros, propendiendo así a una homogeneización que instala sistemas de convivencia que no respetan las diferencias ni la cosmovisión de los pueblos indígenas (Figueroa, 2014; 2015). Son aquellos actores que detentan el poder quienes no han permitido espacios para cambiar sus condiciones. Por otra parte, demuestra las limitaciones de la institucionalidad indígena creada en Chile para implementar políticas que ya contienen sesgos desde sus inicios. Esto supone nuevos desafíos a la construcción de alternativas en el marco del actual proceso constituyente, el que no puede dejar de considerar los mecanismos de participación y toma de decisiones propios de cada uno de los pueblos existentes en nuestro país.

En ese sentido, ya en el año 2009 el Relator Especial de Naciones Unidas para los Pueblos Indígenas señalaba que una tarea principal del Gobierno chileno sería definir los elementos específicos de procedimiento para llevar a cabo la consulta en el proceso de reforma constitucional y el reconocimiento de derechos constitucionales para los pueblos indígenas. Para ello señalaba que este proceso debería ser hecho de tal manera que los mismos pueblos indígenas se mostraran conformes al procedimiento, lo que implica algún tipo de consulta previa sobre la definición del procedimiento. Sin llegar a un nivel mínimo de aceptación del procedimiento por las partes indígenas se hace difícil que la reforma constitucional cuente con la suficiente legitimidad (Anaya, 2009).

En ese contexto, en mayo de este año se inició el denominado "Proceso Constituyente Indígena" que se realiza de manera complementaria al proceso constituyente general, con el objeto de asegurar un marco participativo para el debate sobre sus derechos colectivos e individuales. Para dar seguimiento y apoyo a este 
proceso se constituyó un "Consejo Consultivo y de Seguimiento", conformado por representantes de Organismos Internacionales como PNUD, OIT, ONU, Unicef, entre otros, además de dos consejeros de la Corporación Nacional de Desarrollo Indígena (Conadi), y miembros del Comité Interministerial del Proceso Indígena. Sin embargo, desde diferentes organizaciones indígenas han surgido críticas al proceso, por no respetar los estándares establecidos en el artículo $6^{\circ}$ del Convenio 169 de la OIT en torno a los mecanismos de consulta y de representación indígena.

De acuerdo al análisis comparativo presentado, resulta de gran relevancia respetar los estándares internacionales en términos de dar cuenta de la participación real y efectiva de los pueblos indígenas para no deslegitimar el proceso y sus resultados. Si bien aún se están llevando a cabo las discusiones locales, es necesario resguardar que sean los propios pueblos indígenas quienes definan sus mecanismos de participación, dando cabida a la diversidad que caracteriza a cada uno de los nueve pueblos ("etnias", según la ley) que integran el Estado chileno. La experiencia internacional puede dar algunas luces al respecto.

Como señalaba James Anaya,

una buena práctica es la que se realizó en Australia con la propuesta gubernamental de establecimiento de un "Órgano Nacional Representativo Indígena” en el país. Con miras a la organización de la consulta a los pueblos y comunidades indígenas de los distintos estados y territorios del país, el Gobierno australiano solicitó al comisionado de asuntos indígenas de la Comisión Nacional de Derechos Humanos la organización de un comité indígena independiente responsable de la supervisión de la consulta a nivel nacional, conformado por expertos.

La selección de esos representantes se hizo siguiendo una convocatoria abierta donde el propio comité se encargó de seleccionar a los participantes, resguardando criterios de representación geográfica, género y edad. (Anaya, 2009). Estas y otras experiencias pueden servir de parámetro para encontrar mecanismos apropiados.

Sin embargo, una cuestión relevante es el "poder" como una variable que no puede ser analizada de manera desapegada a este proceso, siendo una dimensión sustantiva para que los pueblos indígenas sean reales actores de la política y del proceso político. En ese sentido, no sólo es importante el rol que juegan los distintos actores en la toma de decisiones, sino el contexto en el que se llevan adelante, de forma específica, las decisiones de política pública indígena. Es allí donde el modelo de Estado-Nación en el que se ha sustentado el desarrollo de la mayoría de los países latinoamericanos, y en particular el chileno, comienza a demostrar sus 
limitaciones para responder a estas demandas de participación y decisión efectiva (Hopenhayn y Bello, 2001).

De esa forma, se estarán reconociendo las miradas y paradigmas de los actores con poder que han promovido la instalación de este modelo como única alternativa posible de convivencia pero que, en la práctica, no ha supuesto poner en debate la colonialidad y sus implicancias para los pueblos indígenas. Es así como estos pueblos aún no recogen los beneficios de esta alternativa, lo que ha llevado al surgimiento de nuevas propuestas de desarrollo que buscan su real empoderamiento en decisiones estratégicas, apostando a cambios importantes en las estructuras de pensamiento actual, lo que se expresa también en las discusiones en torno a la propia reforma constitucional. No atender estas dimensiones podría resultar en un mero ejercicio que no da cuenta de la oportunidad de cambio real a la que nos estamos enfrentando.

\section{CONCLUSIONES}

En el actual proceso que se está viviendo en Chile se requiere asumir, desde el inicio, un debate profundo en torno al tipo de sociedad que se quiere construir, a las concepciones privilegiadas en torno al multiculturalismo, incluso a los puntos de partida desde donde se está incorporando a los pueblos indígenas, quienes, si bien son anteriores a la construcción analítica (incluso artificial) de los países o del propio modelo Estado-Nación, detentan saberes que han sido subvalorados y marginados desde las lógicas occidentales de construcción social y política.

Por lo tanto, se requiere revertir este patrón de relaciones, es decir, las políticas deben propender a una decolonialidad que asegure la reconstrucción de los espacios públicos, considerando realmente a aquellos que han estado marginados en forma histórica de dicho proceso. En este enfoque la modernidad no puede ser analizada sin una referencia a la colonialidad, es decir, a todos aquellos que conforman los "no modernizados", pues es en defensa de la continuidad del proyecto modernizador que se han desarrollado políticas que intervienen sobre territorios, grupos humanos, conocimientos, corporalidades, subjetividades y prácticas, que en su diferencia son catalogadas como "no-modernas" (Restrepo y Rojas, 2010).

La reforma constitucional representa una oportunidad para avanzar en un mayor y mejor reconocimiento de los derechos de los pueblos indígenas en Chile y fortalecer su rol como actores políticos. La consulta y legitimidad del proceso es fundamental para dar real validez al nuevo texto constitucional, de manera que responda a las aspiraciones ancestrales que estos pueblos aún continúan defendiendo. Para ello es necesario asumir las cuestiones presentadas en este texto respecto del 
reconocimiento de derechos políticos, sociales y culturales que están en el centro de sus reivindicaciones, las que no pueden ser obviadas.

¿Estamos dispuestos a dar cabida a estos derechos? ¿Existe la voluntad política para reconocer derechos reivindicados por estos pueblos? ¿Qué sociedad queremos construir? ¿Existe disposición a cambiar las estructuras de poder existentes? ¿Existen espacios para el reconocimiento de los saberes ancestrales? ¿Hemos logrado avanzar hacia un mayor respeto de la diversidad que nos plantean nuestros pueblos originarios? Estas y otras preguntas adquieren relevancia y no pueden dejar de ser asumidas si es que aspiramos a un proceso serio, comprometido con el pluralismo y la interculturalidad en sus expresiones sociales, políticas, económicas y culturales, entre otras.

Hasta el momento, la toma de decisiones se ha fundamentado en la represión de las formas de producción de conocimiento de los pueblos indígenas, en la subvaloración de sus valores y creencias, en el desconocimiento de sus instituciones y en la preeminencia de la "modernidad" como elemento que ha definido los patrones de relación y que no ha permitido la formación de una cultura ciudadana pluralista e interculturada, necesaria en el mundo en el que vivimos (Tubino, 2001). Estamos frente a una oportunidad histórica de hacer el cambio. Cabrá esperar los verdaderos alcances del mismo para juzgar, a la luz de los hechos, si podremos ser ejemplo de una sociedad respetuosa con sus pueblos originarios. 


\section{REFERENCIAS}

Álvarez, Luciana (2010). Más allá del multiculturalismo: crítica de la universalidad (concreta) abstracta. Filosofía Unisinos 11(2), pp: 176-195.

Alkire, Sabina (2005). Subjective quantitative studies of human agency, Social Indicators Research, (74) 1, pp.: 211-217.

Anaya, James (2009). Principios internacionales aplicables a la consulta en relación con la reforma constitucional en Chile. Informe temático a Chile de James Anaya, Relator Especial de Naciones Unidas sobre la Situación de los Derechos y Libertades fundamentales de los indígenas.

Banco Mundial (2014). Los Pueblos Indígenas en América Latina. Balance político, económico y social al término del Segundo Decenio Internacional de los Pueblos Indígenas en el Mundo. BM, Washington.

Bengoa, José (2000). La emergencia indígena en América Latina, Santiago (Chile), Fondo de Cultura Económica.

Bengoa, Jose (2009). ¿Una segunda etapa de la Emergencia Indígena en América Latina? 7. Cuadernos de Antropología Social No 29, pp. 7-22, 2009

Correa Sutil, Sofía (2015). Los procesos constituyentes en la historia de Chile: lecciones para el presente. Estudios Públicos, 137 (verano 2015), 43-85

Figueroa, Verónica (2007). Capital social y desarrollo indígena urbano. Una propuesta para una convivencia multicultural. Los mapuche de Santiago de Chile. Tesis doctoral, ESADE-Universidad Ramón Llull, España.

Figueroa Huencho, Verónica y otros (2015). Nueva institucionalidad indígena y sus repercusiones para la aplicación del Convenio $\mathrm{N}^{\circ} 169$ de la OIT. En Temas de la Agenda Pública, año 10, No 77. Santiago, Chile

Figueroa Huencho, Verónica. (2014). Formulación de políticas públicas indígenas en Chile. Santiago: Editorial Universitaria.

Fondo Indígena (2007). Tendencias de la institucionalidad estatal y las políticas públicas respecto al desarrollo indígena en América Latina y el Caribe. Bolivia. http://www.fondoindigena.org/wp-content/uploads/2011/08/ SerieDesarrollo3.pdf

Hale, Charles (2006). Más que un Indio (More Than an Indian): Racial Ambivalence and Neoliberal Multiculturalism in Guatemala. Santa Fe, New México: School of American Research Press. 
Hall, Gillette y Patrinos, Harry (2004). Pueblos Indígenas, pobreza y desarrollo humano en América Latina: 1994-2004. Banco Mundial, Washington.

Henríquez Viñas, Myriam (2005). Los pueblos indígenas y su reconocimiento constitucional pendiente, en Reforma Constitucional, (Zúñiga Urbina Coordinador), Editorial LexisNexis, Santiago, Chile, 2005, pp. 127 - 145.

Hopenhayn, Martín y Bello, Álvaro (2001). Discriminación étnico-racial y xenofobia en América Latina y El Caribe. Serie Políticas Sociales, No 47, CEPAL: Santiago.

Kelly, Paul (2002). "Introduction: Between culture and equality", en Kelly (ed) Multiculturalism reconsidered: culture and equality and its critics, Cambridge: Polity Press

Kymlicka, Will (2003). La política vernácula. Nacionalismo, multiculturalismo y ciudadanía. Buenos Aires: Paidos.

Martínez Navarro, Emilio (2000). Ética para el desarrollo de los pueblos. Madrid: Trotta.

Meza-Lopehandía, Matías (2010). Reconocimiento Constitucional y Derechos Fundamentales de los Pueblos Indígenas: Con especial referencia al derecho a la consulta. Observatorio Parlamentario, octubre de 2010.

Nash, Claudio y Núñez, Constanza (2015). Reforma Constitucional y Pueblos Indígenas en Chile: Apuntes para el debate. Santiago, Chile.

PNUD (2015). Mecanismos de cambio constitucional en el mundo: Análisis desde la experiencia comparada. PNUD, Chile.

Quijano, Aníbal (2000). Colonialidad del poder, Eurocentrismo y América Latina, en Lander (ed) La colonialidad del saber: eurocentrismo y ciencias sociales. Perspectivas Latinoamericanas. Buenos Aires: CLACSO.

Restrepo, Eduardo y Rojas, Axel (2010). Inflexión decolonial: fuentes, conceptos y controversias. Colombia: Editorial Universidad del Cauca.

Tubino, Fidel (2001). "La impostergable alteridad: del conflicto a la convivencia intercultural", en Castro-Lucic (ed.) Los desafíos de la interculturalidad: Identidad, política y derecho. Vicerrectoría de Investigación y Desarrollo, Universidad de Chile.

Uprimny, Rodrigo (2011). The Recent Transformation of Constitutional Law in Latin America: Trends and Challenges. Texas Law Review 89 (7): 1587-1609

Walsh, Catherine (2006). "Interculturalidad y (de)colonialidad. Diferencia y nación de otro modo", en Desarrollo e interculturalidad, imaginario y diferencia: la nación en el mundo Andino, Quito: Académica. 